\title{
Household energy use and creating awareness: opportunities for ICT
}

\author{
Jeroen Stragier, Laurence Hauttekeete, Lieven De \\ Marez \\ IBBT-MICT-UGent \\ Gent, Belgium \\ Jeroen.Stragier@UGent.be
}

\author{
Jan Derboven, Lieve Laporte \\ IBBT-CUO-KULeuven \\ Leuven, Belgium \\ Jeroen.Stragier@ugent.be
}

\begin{abstract}
Household energy use is growing and energy prices are rising. A growing need exists among households to get more insights into their energy use. ICT can offers solutions here in terms of smart metering and home energy management. Through our research, we wanted to get a view on the adoption potential, willingness to pay and adoption determinants for these tools. Our results indicate a substantial adoption potential for smart metering tools and an existing but limited potential for home energy management systems. An important adoption determinant will be the price of these systems, since they are aimed at helping households to save energy. If the price is higher than the potential savings, interest is likely to be low.
\end{abstract}

Keywords-Smart metering, energy use, adoption determinants, adoption potential

\section{INTRODUCTION}

Households have a growing need for electricity. Although white goods are becoming more and more energy efficient, the growing number of appliances and the growth of multimedia and ICT within homes are a main factor in this situation. More and more households have more than TV set, PC's, laptops but also smartphones, tablets and other new media continue their diffusion within living rooms and bedrooms. A lot of attention goes to making these devices more energy efficient, but in another way, ICT can also help us to become more aware of our energy use. Many tools already exist such as websites or software programs with which meter readings can be kept and analyzed. Home energy management system go beyond this and can provide automated and detailed information on energy use in residential contexts. Automation, mostly in combination with domotics and smart homes are the most advanced features of these systems. The question however rises if households are interested in these systems, simple or advanced, and if they are willing to pay for them. In this paper we try to answer the question of what the opportunities for ICT, and more specifically home energy management system are in households. We therefore measured the adoption intention, willingness to pay (WTP) and adoption determinants in two separate quantitative surveys.

\section{ENERGY USE}

Households have a poor view on their energy use. For most families, the annual energy bill is the only feedback they get and then it's already too late. Nevertheless, this feedback can be an efficient means to become more energy efficient. ICT can provide the enabling tools. Several tools that help households to gain insights into their energy use already exist. These tools range from low budget DYI sets to high end, high cost, fully fledged home energy management systems. These devices are sometimes also called smart metering tools, since they provide the same functionalities as a smart meter would do. Derboven et al. [1] categorized 80 of these tools into 4 distinct categories: "Instructive websites", "Eco-friendly domotics", "Reinterpreted everyday objects" and Home energy management systems. Instructive websites allow keeping of meter readings and can also provide tips and information on how to save energy. Ecofriendly domotics comprise those device that allow automatic heating, lighting or device control and monitoring. Reinterpreted everyday objects are objects that have been redesigned, promoting energy conservation during use. Home energy management systems offer broad functionalities ranging from simple energy use monitoring over providing guidance to full automation of energy using processes in the home. All of these tools are designed for one purpose: to deliver insights into and feedback on the households energy use.

This feedback on energy use has been subject to extensive research. Previous research has shown that active feedback on energy use can effectively encourage households to take energy conserving measures. More specifically related to the enabling effects of ICT, Brandon and Lewis [2] found that the computer assisted feedback provided in one of their 6 feedback condition aided the families in this condition to perform better than the other experimental groups. The energy use in this group dropped significantly: $80 \%$ of the households in the computer assisted condition reduced their energy use significantly. Consistent with these findings, Wood and Newborough [3] found that dynamic feedback on energy use via smart meters and inhome displays reduced the energy use with $10 \%-20 \%$ within the participating households. Ueno et al. [4] tested 
their "Energy Consumption Information System" (ECOIS) at nine houses. The system measured electricity use for the house and for appliance in the house separately. The household members could access their energy use through their computer. The researchers saw a $9 \%$ reduction in the household's overall energy use as an effect of using the ECOIS. The system also proved effective in translating the energy efficient behaviour of the household member to other situations, outside their residential context.

\section{METHOD}

Effectiveness is a very important matter, but to be successful, this kind of technology must be of interest to households. Therefore, in two large scale surveys, the adoption intention and WTP for these systems was investigated. In the first survey, conducted in 2010 with a representative sample of Flanders $(\mathrm{N}=1314)$, the adoption intention of smart metering tools was measured. These represent basic tools that help households monitor and manage their energy use such as power meters, smart plugs... Basically those tools that resort under "Instructive websites", "Eco-friendly domotics", and "Reinterpreted everyday objects" as described above. In the second study, conducted in 2011 ( $\mathrm{N}=858)$, also with a representative sample of Flanders, the same question was asked for home energy management systems.

The method used in the both surveys was the Product Specific Adoption Potential (PSAP)-scale [5-7]. The scale was developed as a valid alternative to traditional singleintent questions used in traditional market research, which systematically lead to over- or underestimation of the adoption potential of innovations. The model has been validated for several innovations [8, 9]. Instead of a single intent question asking for the adoption likelihood of an innovation, three related questions are asked. The adoption intention is measured for optimal and suboptimal product offerings. A calibration heuristic based on the answers on all 3 intention questions assigns the respondent to the appropriate adoption segment [5].

First, the respondents received an introductory text (on smart metering tools in the first survey and on home energy management systems in the second). After reading this text, the first intention question was asked:

"If you would have the opportunity tomorrow to buy a smart metering tool/Home energy management system, to what extent do you think that you would buy this device"? The answering scale provides 5 possible answers:

- I would immediately buy ...;

- There is a large probability that I would buy ...;

- I think I would wait, maybe later;

- I don't think I would buy ...;

- I definitely wouldn't buy.

The respondents were asked to specify an "acceptable price limit" they are willing to pay for a smart metering tool/home energy management system. In the first survey, no pricing limitations were imposed. The respondents were free to give any price they thought was acceptable. In the second questionnaire, categories of price ranges were provided.

After these questions, a second more personalized intention question was asked. This time, a smart metering tool/home energy management system was presented to the respondent at the price they indicated as their ideal price. The same answering categories were provided. Finally, a third intention question was asked. This time, their ideal price was raised with $20 \%$. The last question was meant to measure their adoption intention for a suboptimal product offering.

Based on a calibration heuristic, checking for the consistency in intention statements over the different answers on the 3 PSAP questions, each of the respondents was assigned to one of the adopter segments put forward by Rogers [10]: innovators, early adopters, early majority, late majority and laggards.

For the second survey, we went one step further and asked a subsample of our respondents for their adoption determinants of a home energy management system. Certain determinants can limit or spur a person into adopting an innovation. Various adoption models have studied the effect of adoption determinants on adoption intention [11-16]. For this analysis we have built upon those existing models to come to a set of adoption determinants taken from these models and combined them with some determinants we expect to be specific for home energy management systems. We mainly elaborated on the MATH-model (Model of Adoption of Technology in the Household) [15] for the selection of the adoption determinants. This model is rooted in the Theory of Planned Behaviour [17]. Table 1 describes the each of the determinants that were included in a linear regression model. Each of the determinants were translated into two or more items that were included into a questionnaire and had to be answered by the respondents on a 7-point scale ranging from "totally disagree" to "totally agree".

TABLE I. ADOPTION DETERMINANTS USED IN THE REGRESSION ANALYSIS

\begin{tabular}{|l|l|l|}
\hline $\begin{array}{l}\text { Perceived } \\
\text { Behavioural } \\
\text { Control }\end{array}$ & Cost & $\begin{array}{l}\text { relates to the expected costs of the } \\
\text { innovation }\end{array}$ \\
\hline \multirow{7}{*}{ Safety } & Control & $\begin{array}{l}\text { relates to the degree to which } \\
\text { respondents would like to give control } \\
\text { "out of their hands' to an energy } \\
\text { management system }\end{array}$ \\
\cline { 2 - 3 } & $\begin{array}{l}\text { relates to the degree to which a } \\
\text { respondent thinks it is not safe to have } \\
\text { appliances work in their homes when } \\
\text { they are not around }\end{array}$ \\
\cline { 2 - 3 } & Trialability & $\begin{array}{l}\text { relates to the expectancy of the } \\
\text { consumer to be able to test the } \\
\text { innovation before buying it }\end{array}$ \\
\cline { 2 - 3 } & $\begin{array}{l}\text { Personal } \\
\text { innovativeness }\end{array}$ & $\begin{array}{l}\text { relates to how innovative the respondent } \\
\text { is with regard to new technology }\end{array}$ \\
\cline { 2 - 3 } & Fear & $\begin{array}{l}\text { relates to how "scared" the respondent is } \\
\text { about technological advances }\end{array}$ \\
\cline { 2 - 3 } & Self efficacy & $\begin{array}{l}\text { relates to how the respondent expect } \\
\text { himself to be able to work with the } \\
\text { innovation without help }\end{array}$ \\
\hline
\end{tabular}




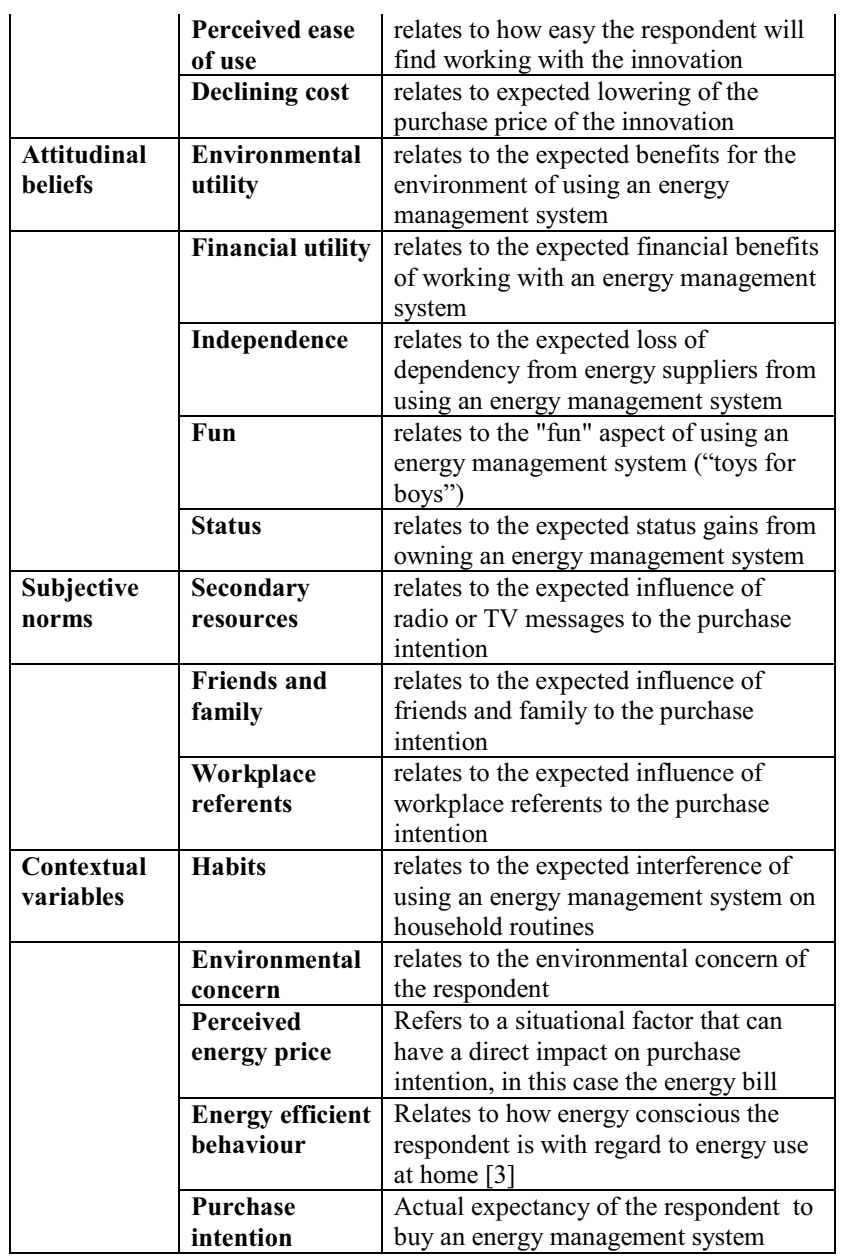

\section{RESUlts}

\section{A. Adoption potential and willingness to pay}

The PSAP-scale allows us to classify our respondents into 5 segments: innovators, early adopters, early majority, late majority and laggards. According to the Rogers [10] the diffusion of innovations through society follows a clockwise pattern where innovators are the first to adopt. They represent $2.5 \%$ of the population, followed by early adopters $(13.5 \%)$, early majority (34\%), late majority $(34 \%)$ and laggards $(16 \%)$. As today's market environment is becoming increasingly competitive however, this single-peaked or clockwise diffusion pattern is more and more inadequate to represent reality. The PSAP-scale was designed for this and allows a better categorization of the adopter segments.

\section{STUDY 1: SMART METERING TOOLS}

For smart metering tools, the results of the PSAP-scale indicate a rather substantial adoption potential. In figure 1, the results of the PSAP-scale are presented and compared to the theoretical distribution of Rogers [10]. It is clear that the PSAP-scale predicts more potential adopters in the short term than would be expected according to diffusion theory. If we take the percentages of the most innovative segments together (innovators, early adopters and early majority), we get a short term market potential of $67 \%$, whereas we would expect $51 \%$ according to diffusion theory. This indicates that there is in fact a substantial interest among Flemish households for tools that provide them with more insight into their energy use. The average WTP in the sample is $€ 87$. This WTP naturally lies higher in the more innovative segments. The average WTP for the innovators is $€ 141$, whereas the laggards, which are least innovative segment, are clearly unwilling to pay a high amount for this kind of tools. We elaborate on these results in the discussion section of this paper.

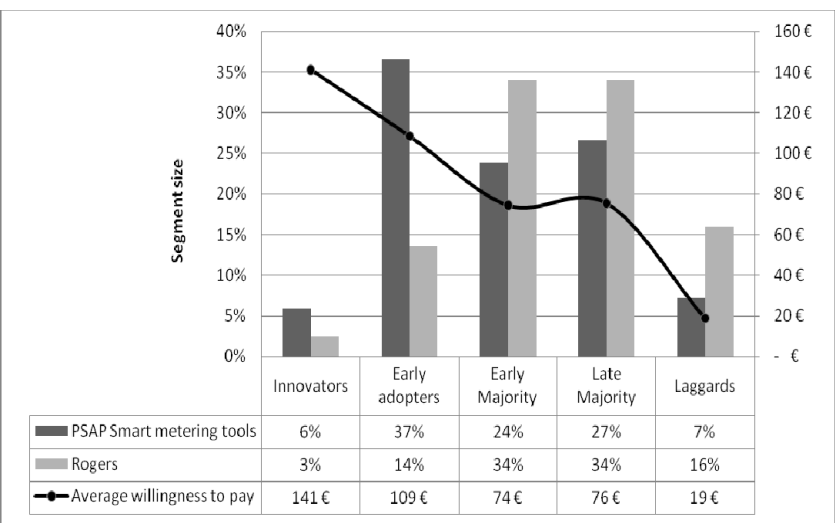

Figure 1. Adoption potential and willingness to pay for smart metering tools

\section{STUDY 2: HoME ENERGY MANAGEMENT SYSTEMS}

The same analysis was done for the second survey $(\mathrm{N}=858)$. Figure 2 presents the results of this analysis. The results indicate that the adoption intention for home energy management system lies lower than that of smart metering tools. The price of a home energy management system is the most important factor in this regard. It would cost significantly more than basic smart metering tools. In the questionnaire, the basic for a system was set to $€ 700^{1}$. If this price was considered too high, the respondent could choose the option to pay a maximum of $€ 500$ or $€ 300^{2}$. Instead of asking number, which was done in the first study, this time, categories of prices $^{3}$ were provided to the respondent. The centre value of these categories was used in the calculation of the average WTP for home energy management systems. The results of the analysis indicate a $29 \%$ adoption potential

\footnotetext{
${ }^{1}$ This price was agreed upon with the industrial project partners ${ }^{2}$ In the questionnaire this was provided in the following answering option: $€ 700$ is too much for me, I would pay maximum $€ 500$ " or " $€ 700$ is too much for me, I would pay maximum $€ 200$."

${ }^{3}$ The categories used were $€ 701-€ 1000, € 1001-€ 1500, € 1501-€ 2000$, $€ 2001-€ 2500$ and $€ 2501-€ 3000$
} 
in the shorter term for these systems. The average WTP varies greatly and shows a significant drop over the different adopter segments. In fact, late majority and laggards are not willing to pay the basic price of a home energy management system.

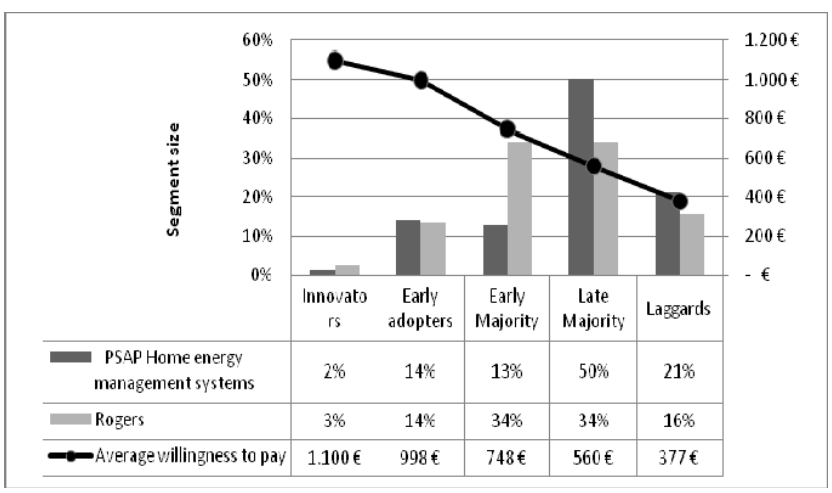

Figure 2. Adoption potential and willingness to pay for home energy management systems

\section{A. Adoption determinants}

As indicated above, an adoption determinant analysis was performed for home energy management systems. While the total sample size was 858 respondents, only a subset of 289 respondents was used for practical reasons. The adoption determinants described in table 1 were measured on a 7point- scale ranging from "totally disagree" to "totally agree".

All these adoption determinants were entered into a linear regression analysis with Purchase intention as the dependent variable. The results of the regression analysis are presented in table 7. For statistical reason, the three determinants underlying subjective norms were taken together in one factor, named "subjective norms". This factor presents the expected influence of peers on the purchase intention.

The model significantly predicted adoption intention of home energy management systems as depicted in table 2. The total variance explained by the model is $62.7 \%$.

TABLE II. RESULTS OF THE LINEAR REGRESSION ANALYSIS

\begin{tabular}{|l|c|c|c|}
\hline & Beta & t & Sig. \\
\hline Financial utility & 0,313 & 4,187 & 0,000 \\
\hline Subjective norms & 0,289 & 4,838 & 0,000 \\
\hline Innovativeness & 0,204 & 3,524 & 0,000 \\
\hline Cost & $-0,205$ & $-4,665$ & 0,000 \\
\hline Perceived energy price & $-0,15$ & $-2,882$ & 0,004 \\
\hline Energy efficient behaviour & 0,131 & 3,142 & 0,002 \\
\hline Trialability & 0,122 & 2,412 & 0,017 \\
\hline Environmental utility & 0,097 & 1,439 & 0,151 \\
\hline
\end{tabular}

\begin{tabular}{|l|c|c|c|} 
Self efficacy & $-0,061$ & $-0,806$ & 0,421 \\
\hline Habits & 0,057 & 1,399 & 0,163 \\
\hline Environmental concern & $-0,054$ & $-1,226$ & 0,221 \\
\hline Independence & 0,051 & 1,081 & 0,281 \\
\hline Fun & 0,041 & 0,673 & 0,502 \\
\hline Fear & $-0,038$ & $-0,815$ & 0,416 \\
\hline Control & 0,03 & 0,673 & 0,502 \\
\hline Declining cost & 0,023 & 0,501 & 0,616 \\
\hline Perceived ease of use & $-0,011$ & $-0,18$ & 0,857 \\
\hline Safety & $-0,011$ & $-0,248$ & 0,805 \\
\hline Status & $-0,004$ & $-0,082$ & 0,935 \\
\hline
\end{tabular}

More specifically, this means that if someone expects to gain financial benefits from using an energy management system, they will have a higher purchase intention. Peers (subjective norms) are also expected to have a significant influence, as well as a person's innovativeness. The more innovative a person considers himself; the more likely they are to purchase an energy management system. The expected cost is also a highly significant determinant. As can be seen in table 2, it has a negative impact on the adoption intention means that the higher someone expects the price of an energy management system to be, the less likely they are to purchase it.

Three other factors, which have a somewhat significant impact, are the perceived energy price, the energy efficient behaviour of the customer and the expected opportunity to try out the energy management system. A somewhat unexpected outcome is the negative influence of perceived energy price. This would suggest that if a respondent believes that he pays a lot for energy, this would have a negative impact on the purchase intention for an energy management system. Although the influence of this determinant is rather low, this is still a somewhat surprising outcome. An outcome that is less surprising is the positive effect of energy efficient behaviour on purchase intention. A part of this energy efficient or "energy conscious" behaviour is monitoring energy use. So, those who are currently already monitoring their energy use to some extent are more likely to be interested in buying an energy management system. The last determinant that appears to be influential is the expected trialability of the system. If a customer expects that he will be able to test it first, he considers himself to be more likely to buy the system.

\section{DISCUSSION AND CONCLUSION}

The results of our two surveys are clear. There is definitely a potential for smart metering tools in Flanders. However, the price of these tools plays an important role in this case. For a household, the main outcome of buying these tools is to lower the energy bill. If the tools that are supposed to help them cost more than what they can save in the middle to long term, they become a lot less interesting. From the first survey it was clear that there is interest in smart 
metering tools, but not at a high price. The innovators, the most innovative segment, are willing to pay $€ 141$ on average, while the laggards, which are the least innovative segment, are only willing to pay $€ 19$. For home energy management systems, the most advanced form of energy monitoring, the adoption potential is substantially lower. However, there are families that are willing to pay more than $€ 700$ euro for these systems. The adoption determinant analysis however, showed that price will have a negative impact on the adoption intention the outcome of buying such a system, which was illustrated by the adoption determinant analysis, must be that it results in financial profit. Of course several other factors will determine the adoption of these systems. Innovativeness seems to be an important one, but also structural factors will be of importance. A system that is fully integrated in the building will only be possible in new buildings or large renovations.

To conclude, we can say that there surely is in an interest in smart metering tools in Flanders, which indirectly illustrates the households' need to have more insight into their energy use. There are definitely opportunities for ICT in this matter, but only if it comes at a price that can be won back. If the savings are in relation to the cost, adoption intention will probably be quite low.

\section{ACKNOWLEDGEMENTS}

The IBBT SmartE project is a project cofunded by IBBT (Interdisciplinary institute for Technology). A research institute founded by the Flemish Government. Companies and organizations involved in the project are IBBT, IBBTiLab.o UGent-MICT, UGent-IBCN, KULeuven-CUO, KULeuven-ESAT-Electa, VITO, VUB-SMIT, Telenet, SPELuminus, Alcatel-Lucent Bell, Niko, Ferranti and Xemex, with project support of IWT.

\section{REFERENCES}

[1] J. Derboven, L. Laporte, D. Geerts, and D. De Grooff, "Competitive Analysis in the Semiotic Design Process: The Smart-E Case Study," 2012.

[2] G. Brandon and A. Lewis, "Reducing Household Energy Consumption: A Qualitative and Quantitative Field Study," Journal of Environmental Psychology, vol. 19, pp. 75-85, 1999.

[3] G. Wood and M. Newborough, "Dynamic energyconsumption indicators for domestic appliances: environment, behaviour and design," Energy and Buildings, vol. 35, pp. 821-841, 2003.

[4] T. Ueno, F. Sano, O. Saeki, and K. Tsuji, "Effectiveness of an energy-consumption information system on energy savings in residential houses based on monitored data," Applied Energy, vol. 83, pp. 166-183, 2006.

[5] L. De Marez, "Diffusie van ICT-Innovaties: Accurater Gebruikersinzicht Voor Betere
Introductiestrategieën," Gent: Universiteit Gent, 2006.

[6] L. De Marez, T. Evens, and J. Stragier, "Diffusion theory vs. today's ICT environment," Observatorio vol. 5, pp. 175-202, 2011.

[7] L. De Marez and G. Verleye, "ICT-innovations today: making traditional diffusion patterns obsolete, and preliminary insight of increased importance," Telematics and Informatics, vol. 21, pp. 235-260, 2004.

[8] T. Evens, D. Schuurman, L. De Marez, and G. Verleye, "Forecasting broadband Internet adoption on trains in Belgium," Telematics and Informatics, vol. 27, pp. 10-20, 2010.

[9] L. De Marez, P. Vyncke, K. Berte, D. Schuurman, and K. De Moor, "Adopter segments, adoption determinants and mobile marketing," Journal of Targeting, Measurement and Analysis for Marketing, vol. 16, pp. 78-95, 2007.

[10] E. M. Rogers, Diffusion of innovations, 4th ed. New York (N.Y.): Free press, 1995.

[11] V. Venkatesh, M. Morris, G. Davis, F. Davis, W. DeLone, E. McLean, C. Jarvis, S. MacKenzie, P. Podsakoff, and W. Chin, "User acceptance of information technology: Toward a unified view," Information Management, vol. 27, pp. 425-478, 2003.

[12] F. Davis, "Perceived Usefulness, Perceived Ease of Use, and User Acceptance of Information Technology," MIS Quarterly, vol. 13, pp. 319-340, 1989.

[13] F. Davis, R. Bagozzi, and P. Warshaw, "User Acceptance of Computer Technology: A Comparison of Two Theoretical Models," Management Science, vol. 35, pp. 982-1003, 1989.

[14] F. Davis, "A technology acceptance model for empirically testing new end-user information systems: theory and results," Cambrigde, MA: Massachussets Institute of Technology, 1986.

[15] S. A. Brown and V. Venkatesh, "A Model of Adoption of Technology in the Household: A Baseline Model Test and Extension Incorporating Household Life Cycle," Management Information Systems Quarterly, vol. 29, p. 4, 2005.

[16] S. A. Brown, V. Venkatesh, and H. Bala, "Household technology use: integrating household life cycle and the model of adoption of technology in households," The Information Society, vol. 22, pp. 205-218, 2006.

[17] I. Ajzen, "The theory of planned behavior," Organizational Behavior and Human Decision Processes, vol. 50, pp. 179-211, 1991. 